\title{
ADMINISTRATION OF CORTICOSTEROIDS TO PREVENT SEVERE OVARIAN HYPERSTIMULATION SYNDROME IN PATIENTS UNDERGOING GnRH AGONIST DOWN REGULATED ICSI CYCLES
}

Ashraf Hany Abd El Rahman, M.D., Hadeer Aly Abbassy. M.D.

Obstetrics \& Gynecology Department, Clinical and Chemical pathology departrment, faculty of medicine, Alexandria University, Alexandria, Egypt

\section{ABSTRACT}

Objectives : To test if Corticosteroids (methylpredniosolone) reduces and prevents OHSS in women undergoing IVF-ICSI cycles.

Design : Prospective, randomized study.

Setting : Shatby hospital for women and Elmadina IVF-ICSI center.

Patients : 67 women undergoing IVF-ICSI from May 2006 to April 2007.

Intervention : Corticosteroid (Methylpredinsolone), was given at the day of oocyle recovery till the day of pregnintey test then the dose was tapered.

Main Outcome Measure(s) : Occurrence of OHSS and pregnancy.

Results : A significantly lower proportion of methylprednisolone recipients than untreated participants developed OHSS ( $20 \%$ vs. $43 \%$ ). Treatment recipients had more oocytes retrieved and moe embryos fertilized than did untrealted participants.

Conclusions: Given the corticosteroid (methylprednisolone) is a well established and safe medication. This study provides evidence that the use of methylprednisolone in the prevention of OHSS in women undergoing assisted reproduction, is successful and without affection of the pregnancy rate.

Key words : Ovarian hyperstimulation syndrome, in vitro fertilization.

\section{INTRODUCTION}

Ovarian hyperstimulation syndrome (OHSS) is an iatrogenic complication of ovulation induction. Its cardinal features are marked ovarian enlargement and acute third-space fluid sequestration. The fluid shift from the intra- to the extravascular spaces in response to the increase in capillary permeability contributes most to the mobidity associated with OHSS ${ }^{(1)}$.
The syndrome almost always presents either 3-7 days after HCG administration in susceptible patients (carly onset) or during carly pregnancy, 12-17 days after hCG administration (late onset). Early OHSS can to some extent be predicted by pre-ovulatory indices of ovarian response, in time to institute preventive measures such as cancellation ${ }^{(2)}$. Late OHSS does not relate strongly to pre-ovulatory ovarian response, making it difficult for clinicians to 
identify the cycles in which it is likcly to occur (3). In the original description of OHSS, the late form was observed only in cycles with multipic gestations ${ }^{(4)}$, with a trend toward an increase in the severity of the discase with an ienrease in the number of gestational sacs (5).

Several arlicles have reviewed the cpidemiological, hormonal and ultrasonographic characteristics of patients susceptible to OHSS (6-12) Despite the many years of clinical experience, however, the pallhophysiology of OHSS remains poorly understood, and there is no reliable test to predicl which patients will develop severe OHSS ${ }^{(13)}$. When all the accepted predictive variables were combined, the prevalence of severe OHSS in the ostensibly high-risk patients was only $-20 \%(12,14)$, an extremely low valuc for reliable prediction.

No definitive ticatment of OHSS currently exists, which makes prediction of the risk of development and prewention exepptionally important. Patierts at risk for OHSS should be identificd before trealment becomes necessary. Women with the polycystic ovarian syndrome and high follicle reserve have been shown to be at pitticular risk for OHSS, cven when endocrine test results do nol suggest polycystic ovarics (15).

The ovarian liyperstimulation syndrome is issocinted wilh the necklace sign on ultrasonograplyy and is generally associated with high preovulatory estrogen levels. Nevertheless, it sometimes occurs in the presence of normal or low E2 levels $(7,16,17)$. An association has also been reported between the number of follicles, particularly small and medium-sized follicles, and the occurrence of OHSS $(16,18)$. It is generally accepted that patients with botl a large number of ovarian follicles and high prcovulatory serum $E_{2}$ concentrations arc at increased risk for the syndrome. It was once thought that incorporation of a GnRH agonist into ovarian stimulation regimens would reduce the incidence of
OHSS. To the contrary, several studies have shown that use of GnRH agonist, in conjunction with higher doses of fertility drugs to maximize assisted reproductive technology success rates, is associated with a higher prevalence of OHSS (19-21). Diverse mechanisms have been postulated to explain this finding, including the initial flare-up effect, inhibition of premalure lutcinization, and a direcl action of $\mathrm{GnRH}$ agonist on the ovarian stroma. In addition, the use of pituitary down-regulation requires $\mathrm{HCG}$ to induce ovulation, which increases the risk for OHSS over endogenous LH for ovulation (18,22). Recent studies, however, have not substantiated predictions of an increase in the incidence of OHSS ${ }^{(23)}$, perhaps because preventive measures werc taken ${ }^{(19)}$. Because HCG is considered the major trigger for development of OHSS, withholding HCG would be one method of avoiding OHSS. To achieve this, the IVF cycic is abandoned and a new cycle is commenced 1 or 2 months later ${ }^{(9)}$. Alternatively, gonadotropin actministration can be discontinued until serum $\mathrm{E}_{2}$ values return to safe levels (coasting). However, in a cohorl study of 252 consecutive IVF cycles, the risk for severe OHSS was shown to be multifactorial and was not always prevented by withholidng HCG (24). It has been suggested that i.v. administration of human albumin around the time of oocyte retricval might reduce the development of OHSS in high-risk women (17). Albumin contributes significantly 10 plasma colloid osmotic pressure. Other sludies have suggested that i.v. administration of albumin at oocyte retrieval does not prevent severe OHSS. especially in cases associated with pregnancy $(25,26)$. Corticosteroids haye been already used in IVF and infertility, for example, to treal recurrent abortions of autoimmune eliology and to treat endometriosis (27).

So the aim of this study is to determine whether administration of a corticosteroid to patients at high risk for OHSS helps reduce the development of the disease. 


\section{MATERIALS \& METHODS}

This study included 40 female patients between May 2006 and April 2007; it was approved by our institution's Ethical Committee, and all participants signed a written consent form.

A long protocol was used for ovulation induction starting with subcutanous daily injections of buserelin acetate (Hoechst UK Limited, Hounslow, Middlesex, UK), 300 micrograms, on Day 21 of the preceding cycle. Recombinant FSH (Puregon, Organon Laboratories Ltd, UK) injections were administered after the third day of the subsequent cycle, at an initial dose of $150 \mathrm{IU}$; the doses were subsequently adjusted on the basis of responses and monitoring with transvaginal scan, and serum estradiol levels.

The duration of FSH stimulation ranged from 10 to 12 days, and serial estradiol estimations and ultrasound scans were performed on alternate days between Days 5 and 10 of the cycle and as necessary thereafater. Only patients at risk of developing OHSS, defined by the development of 20-30 follicles $>12 \mathrm{~mm}$ in diameter, and retricveal of $>20$ oocytes, were included. Once the decision to administer HCG was taken, patients were immediately allocated into two groups based on a computer randomization:

a) The study group initially consisted of 35 patients, The regimen consisted of administration of corticosteroids (bolus i.v. dose of methylprednisolone, $1 \mathrm{~g}$ ), starting on the day of egg collection and on the day of embryo transfer. Followed by daily administration of methylprednisolone, $16 \mathrm{mg}$, till the day of pregnancy test (day 13 after the embryo transfer) then the dose was tapered. Luteal support was provided by daily intravaginal administration of progesterone tables.

b) The control group was also initially composed of 32 women receiving a placebo tablet from the day of egg collection till the day of pregnancy test in addition to the luteal support previously mentioned in the study group.

All high-risk patients were seen 5 days after ET to determine whether they had developed elinical hyperstimulation. Ultrasonography was also performed. The patients were then examined every 2 days.

Ultrasonography and Laboratory Assays:

All ultrasonographic measurements were performed by A $6.5 \mathrm{MHz}$ vaginal probe (Voluson 730 Pro V, General Electric, Madrid, Spain) .

Estradiol was measured by using the commercially available Coat-a-Count recombinant immunoassay kit (Diagnostic Products Corp., Los Angeles, CA).

To evaluate the risk of hemoconcentration, we measured hemoglobin, hematocrit, and leukocyte count. Moreover, renal (creatinine) and liver [transaminases: aspartate 6 aminotransferase $(\triangle S T)$; alanine aminotransferase (ALT) functions, and electrolytes $(\mathrm{Na}, \mathrm{K})$ were analyzed to ascertain the severity of the syndrome. We centered our attention on analyzing the incidence of moderate and severe OHSS, which were identified according to our modified (28) classification of Golan et al (29). Moderate OHSS was confirmed when a patient presented ultrasonographic evidence of ascites, while diagnosis of severe OHSS required clinical evidence of ascites and/or hydrothorax and breathing difficulties, or one of the following criteria:

a) increased blod viscosity: hemoglobin $\geq 15 \mathrm{~g} / \mathrm{dl}$, hematocrit $\geq 45 \%$; or leukocyte count $\geq$ $20,000 / \mathrm{mm}^{3}$.

b) coagulation abnormality;

c) diminished renal perfusion and function (serum creatinine levels $>1.2 \mathrm{mg} / \mathrm{dl}$ );

d) liver dysfunction: defined when transaminases (AST or ALT) were $>40 \mathrm{U} / \mathrm{ml}^{(28,29)}$. 
Statistical Analysis:

Statistical analysis was performed using the $\chi^{2}$, or l-test as appropriate. All P-values quoted with values $<0.05$ indicated statistical significance. Analyses were performed using the SPSS statistical package (SPSS, Inc, Chicago).

\section{RESULTS}

The age and duration of infertility in both high-risk groups (Table II) did not differ signilicantly, but the treated group had on average more previous IVF trials than did the untreated group $(P<05)$. The treated group had a significantly higher E2 concentration, more oocytes retrieved, and more embryos fertilized than did the untreated group $(P<05)$.

A significantly lower proportion of treated patients than untreated patients developed moderate degree of ovarian hyperstimulation syndrome (OHSS) and ascites respectively (20\% vs. $43 \%$; $P=$ $0.094), \&(25 \%$ vs $59 \%)$ as shown in table I.
The relative risk for OHSS by not using methylprednisolone but having high risk was 2.3 (95\% CI, 1.6-3.4). Taking into account all participants, the percentage of high-risk women who developed OHSS decreased from $3.5 \%$ to $1.0 \%$ with use of methylprednisolone. In this case, the relative risk for OHSS by not using methylprednisolone is 3.5 (95\% CI, 1.1-5.0). No woman who was not at high risk for OHSS developed the disease before or after use of methylprednisolone.

The proportion of treated high-risk women who had an ongoing pregnancy was slightly but not significantly higher than the corresponding proportion of untreated women $(60.0 \%$ vs. $51.2 \%)$. In the untreated group, the incidence of OHSS was equally divided between women with and without established clinical pregnancy. In contrast, four of the five women treated with methylprednisolone who developed OHSS had an ongoing pregnancy. The difference in the incidence of OHSS between the two groups statistically favored the treatment group both in the presence and in the absence of an ongoing pregnancy.

Table I : Signs and symptoms of moderate and sever ovarian hyperstimulation in both groups.

\begin{tabular}{|l|c|c|c|}
\hline & Study $(\mathbf{n}=\mathbf{3 5})$ & Control $(\mathbf{n}=32)$ & P value \\
\hline * Hemoconcentration & 2 & 5 & NS \\
\hline ** Renal dysfunction & 0 & 0 & - \\
\hline *** Liver dysfunction & 2 & 2 & NS \\
\hline Thrombocmbolism & 0 & 0 & 0.005 \\
\hline Ascites $>9 \mathrm{~cm}^{2}(\%)$ & $9(25)$ & $19(59)$ & 0.04 \\
\hline Moderntc OHSS $(\%)$ & $7(20)$ & $14(43)$ & NS \\
\hline Sever OHSS $(\%)$ & $4(11)$ & $6(18)$ & \\
\hline
\end{tabular}

* Hematocrite $>45 \%$

** Creatinine $>1.2 \mathrm{mg} / \mathrm{dl}$

**** ALT or AST $>40 \mathrm{u} / \mathrm{ml}$ 
Table II : Study characteristics ( \pm S.D).

\begin{tabular}{|l|c|c|c|}
\hline & Test $(\mathrm{n}=35)$ & Control $(\mathrm{n}=32)$ & P value \\
\hline Agc & $30.5 \pm 3.9$ & $30.9 \pm 4.7$ & NS \\
\hline Duration of infertility & $4.6 \pm 2.8$ & $4.4 \pm 2.5$ & NS \\
\hline Day of HCG & $11.6 \pm 1.5$ & $11.6 \pm 1.4$ & NS \\
\hline E2 conc (pg / ml) & $4.848 \pm 1.482$ & $3.727 \pm 1.329$ & $<.01$ \\
\hline No of oocytes retricved & $28.7 \pm 8.6$ & $24.0 \pm 9.9$ & $<.01$ \\
\hline No of eggs fertilized & $15.4 \pm 64$ & $12.1 \pm 5.2$ & $<.01$ \\
\hline No of emb. Transf. & $3.9 \pm 1.2$ & $4.0 \pm 1.0$ & NS \\
\hline
\end{tabular}

\section{DISCUSSION}

The reduction in the proportion of treated women who developed OHSS ompared with untreated women was significant. Furthermore, the effectiveness of treatment with methylprednisolone was independent of the number of IVF trials and the cause of infertility, even though both of these factors aflect the development of OHSS. We believe that the reduction in OHSS that we observed is largely duc to administration of methylprednisolone. This corticosteroid protocol is used in diverse situations in which immunosuppressive therapy is required. The incidence of OHSS in the untreated group is similar to that which Tan et al ${ }^{(30)}$ observed in their untreated patients, even though the selection criteria were applied at different periods.

Recent studies have suggested that the increased propensity of ovaries to become overstimulated is duc to increased expression of the vascular endothelial growth factor in the stroma of the ovary, which itself has increased blood flow as demonstrated by color Doppler ultrasonography (31,32): The proposed mechanism is as follows (33). As a result of multifollicular development effected by gonatdotropin stimulation and their massive luteinization induced by $h \mathrm{CG}$, excessive production of vascular endothelial growth factor occurs, which leads to the desirable effect of extensive perifollicular neovascularization. This, however, is aceompaied by the escape of follicular vascular endothelial growth factor into periloneal cavily and blood stream, causing disruption of functional integrity of blood vessels and massive fluid shift into the third compartment (i.e., clinical hyperstimulation syndrome). This syndrome may lead to intravascular hypovolemia; development of edema, ascites, hydrothorax, or hydropericardium; and impairment of cardiac, renal, pulmonary, and liver functions. Reports indicate that the ability of corticosteroids to reduce edema stems in part from their ability to abolish expression of vascular endothelial growth factor (34). The site of action of glucocorticoids is the microcirculation and inflammation (35). These agents inhibit vasodilatation, thereby preventing the increase in blood flow. They also prevent increases in vascular permeability. 


\section{CONCLUSION}

In Conclusion, by using methylprednisolone, we avoided use of coasting. We did not withhold hCG and transferred embryos in all cycles, thereby improving pregnancy rates per cycle. The etiology of OHSS and the mechansim by which methylprednisolone may have a preventive effect on its development is not yet fully clarified. However, our results indicate that early identification of high-risk patients and immediate commencement of treatment with methylprednisolone helps decrease the incidence of OHSS and therfore avoid hospitalization, reduce cycle cancellations, and improve the cost-effectiveness of IVF cycles.

\section{REFERENCES}

1. Navot D, Bergh PA and Laufer N. The ovarian hyperstimulation syndrome. In Adashi E, Rock JA, and Rosenwaks Z (eds) Reproductive Endocrinology, Surgery, and Technology. Lippincott-Raven Publishers, Philadelphia, (1996): pp. 2215-2232.

2. Hancock KW, Stitch SR, Oakey R, Scott JS, Levell MJ and Ellis FR Ovulation induction. Problems of prediction of response to gonadotrophin. Lancet 1970; 2, 482-485.

Mathur RS, Akande AV, Keay SD et al. Late onset OHSS after ovarian stimulation is poorly predicted by peak oestradiol concentration and number of oocytes collected. Hum Reprod 1997; 12 (Abstr Book 1), R-229.

4. Lyons CA, Wheeler CA, Frishman GN, Hackett RJ, Seifer DB and Hanning RVJ Early and late presentation of the ovarian hyperstimulation syndrome: two distinct entities with different risk factors. Hum Reprod 1994; 9, 792-799.

5. Mathur RS, Joels LA, Jenkins JM, Hunt LP and Jenkins JM. Ovarian hyperstimulation syndrome may be more likely if multiple pregnancy followd assisted conception. Acta Genet Med Gemellol 1995; 44. 233-235.

6. Blankstein J, Shale J, Saadon T, Kukia EE, Rabinovici J, Pariente C, Lunenfeld B, Serr DM and Mashiach S (6) Ovarian hyperstimulation syndrome: prediction by number and size of preovulatory ovarian follicles. Fertil Steril 1987; 47, 597-602.

7. Asch RH, LiH, Balmaceda JP, Weckstein LN and Stone SC. Severe ovarian hyperstimulation syndrome in assisted reproductive technology: definition of high risk groups. Hum Reprod 1991; 6, 1395-1399.

8. Navot D, Bergh PA and Laufer N. Ovarian hyperstimulation syndrome in noel reproductive technologies: prevention and treatment. Fertil Steril $1992 ; 58,249-261$.

9. Navot D, Berg, P, Laufer $N$. The ovarian hyperstimulation syndrome. In: Adashi E, Rock J, Rosenwaks Z (eds). Reproductive endocrinology, surgery and technology. Vol. 2. Philadelphia: Lippincott-Raven; 1995: 2215-32.

10. Morris RS, Paulson RJ, Sauer MV and Lobo RA. Predictive value of serum oestradiol concentrtions and oocyte number in sever covarian hyperstimulation syndrome. Hum Reprod 1995; 10 , $811-814$

11. Zalel Y, Orvieto R, Ben-Rafael Z, Homburg R, Fisher $\mathrm{O}$ and Insler $\mathrm{V}$. recurrent spontaneous ovarian hyperstimulation syndrome associated with polycystic ovary syndrome. Gynecol Endocrinol $1995 ; 9,313-315$

12. Delvigne A and Rozenberg S. Epidemiology and prevention of ovarian hyperstimulation syndrome (OHSS): a review. Hum Reprod Update 2002; 8. $559-577$

13. American Society for Reproductive Medicine Practice Committee. Ovarian hyperstimulation syndrome. Fertil Steril 2004; 82, S81-S86.

14. Orvieto $R$ and Ben-Rafael Z. Role of intravenous albumin in the prevention of severe ovarian hyperstimulation syndrome. Hum Reprod 1998; 13, 3306-3309. 
15.Enskog A, Henriksson M, Unander M, Nilsson L, Branustrom M. Prospective study of the clinical and laboralory paramelers of paticnts in whom ovarian hyperstimulation syndrome developed during controlled ovaian hyperstimulation for in vitro fertilization. Fertil Steril 1999; 71: 808-814.

16. Delvigne A, Vandromme J, Barlow P, Lejeunne B, Leroy F. Are there predictive eriteria of complicated ovarian hyperstimulation syndrome in IVF? Hum Reprod 1991; 6: 959-962.

17. Navot D, Relon A, Birkenfield A, Rabinwitz R, Brezezinski A, Margalioth E. Risk factors and prognostic variables in the ovarian hyperstimulation syndrome. Am J Obste! Gynecol 1988; 15: 210-215.

18. Mathur R, Jocls L, Akande A, Jenkins J., Birkenfeld $A$, Relon $A$, et al. The prevention of ovarian hyperstimultion syndrome. Br J Obstel Gynaecol 1996; 103: 740-746.

19. forman R, Frydman R, Egan D, Ross C, Barlow D. severe hyperstimulation syndrome using agonists of gonadolropin-seleasing llormone for in vitro fertilizaljon a European series and a proposal for prevention. Fertil Steril 1990; 53: 502-509.

20. Abramoy Y, Elchala U, Schenker JG. An epidemic of severe OHSS: a price we have to pay? Hum Reprod 1999; 14: 2421-2422.

21. Al-Ramahi M. Decreasing the risk of ovarian hyperstimulation syndrome. Hum Reprod 1999; 14: 2181-2185.

22. Shoham Z, Schachter M, Loumaje E, Weissman A, MacNamee $M$, Insler $V$. The lutcinizing hormone surge-lhe final slage in ovulation induction: modern aspects of ovulation triggering. Fertil Steril 1995; 64: 237-251.

23. Grudzinskas J, Egbase P. Prevention of ovarian hyperstimultion syndrome: novel strategies. Hum Reprod 1998; 13: 2051-2053.

24. Lee C, tummor I, Marlin J, Nisker J, Power S, tekpetcy F. Does withholding gonadotropin administration prevent severe ovarian hyperstimulation syndrome? Hum Reprod 1998; 13: 1157-1158.
25. Nduk we G, Thornton S. Fishel S, Dowell K, Aloum M. Severe oxarian lyperstimulation syndrome: is it really preventable by prophylactic, intravenous albumin? Fertil Steril 1097; 68: 851-855.

26. Ben-Chetrit A, Eldar-Gown T, Gal M, Huera $M$. Mimon l, Algur N, et all. The guestionnble use of albumin for the prevention of ovarian hyperstimalation syndroem in an IVI: programme: it randomized placebo-controlled trial. Hum Repren? $2001 ; 16: 1880-1884$.

27. Kim C, Chice 1.t, Kilng B, Ching Y, Mok J. 'lhe immunotheralpy duringin vitro licritization and cmbryo transfer cycles in infertile patients will cndometriosis, J Obslet Gynecol Res 1997; 23: $463-470$

28. 23. Bellver J, Munoz, EA, Ballesteros A, Reis Sailles S, Bosch E, Simón C, Pellicer A. Remolui J. 200,?. Intravenous albumin does not prevent moderate-severe ovarian hyperstimulntion syndrom ein high-risk IVT paticuts: a randomized-controlled sludy. Hum Reprod 18: 2283-228B.

29. 24. Golan A, Ron-el R, Ilerman A, Solfer Y, Wointabub $Z$, Cispi li 1989 Ovarian hyperstimulation sindrome: and update review. Obstet Gynecol Surv 44: 430-440.

30. Tan S, Balen $A$, Hussein E, Camplell $S$, Jaculs $B$. The administration of glucocorticoids for the prevention of ovarjan hyperstimulation syndromein in vitro fertilization: a prospective randomized study. Ferti]Sterif 1992; 58: 378-383.

31. Abramov Y, Barak V, Nisman B, Schenkel JG. Vascular endolhelial growth factor plasmal levels correlate to the clinicat picture in severe ovarian hyperstimulation syndrome. Fertil Stcril 1997; 67: 261-265.

32. 29. Ludwig $M$, Jelkmann W, Bauer O, Diedrich K. Prediction of severe ovarian hypersimulation syndrome by free serum vascular endolhelial growl) factor concentraion ont he day of human chorionic gonadotrophin administration. Hum Reprod 199y; [4: 2437-2441.

33. 30. Neulen J. Wenze| D, Hornign $C$, Wünsch $E$, Weissenborn $U$, Grunwald $K$, ${ }^{*}$ el al, Poor 
responder-high responder: the importance of soluble vascular endothclial grooowth factor receptor 1 in ovarian stimulation protocois. Hum Reprod 2001; 16: $621-626$.

34. 3I. Nauck M, Karakioulakis G, Perruchoud A, Papakonstationou E, Roth M. Corticosteroids inhibit the expression of vascular endothelial growth factor gene in human vascular smooth muscle cells. Eur J Pharmacol 1998; 12: 309-315.

35. 32. Pertetti $M$, Ahluwalia A. The microcirculation and inflammation: site of action of glucocorticoids. Microcirculation 2000; 7: 147-161. 